\title{
Simulating the formation of wax deposits in wells using electric submersible pumps
}

\author{
A.N. Aleksandrov \\ Engineer, Saint Petersburg Mining University, Saint Petersburg, Russia \\ M.A. Kishchenko \\ Master student, Saint Petersburg Mining University, Saint Petersburg, Russia \\ Thang Nguyen Van \\ Postgraduate student, Saint Petersburg Mining University, Saint Petersburg, Russia
}

\begin{abstract}
In this paper, based on the known physicochemical characteristics and the component composition of the reservoir high-wax oil from $\mathrm{D}_{2 \mathrm{ef}}$ formation of the Kirtaelsky field, a phase behavior model of the studied high-wax oil was developed through the Multiflash Wax module, which allows us to determine the conditions for phase transition of paraffinic hydrocarbons in the gas-liquid mixture. It is established that for the given conditions, the closest to the actual value of the depth of organic deposit formation was obtained through the complex mechanistic model of the vertical multiphase flow OLGAS. The nature of the change in WAT along the wellbore was determined. The changes were highly noticeable when creating a depression in the reservoir and increasing the pressure in the electric submersible pumps (ESP) together with the degassing process of well products. A study focused on the influence of operating parameters of a well equipped with an ESP on conditions leading to the wax formation was conducted. Practical recommendations for the conditions under consideration were obtained.
\end{abstract}

\section{INTRODUCTION}

A principal challenge in many oil industry production situations is paraffin wax. Up to $75 \%$ of the world's oil suffers when wax precipitates out and solidifies in formation pores and fluid flow channels, at the wellbore, on the sidewalls of wells, in the tubing, casings, pump strings, and processing system. Wax deposition is costly and one of the oil industry's most expensive inconveniences, leading to dramatic reductions in production, equipment failures, loss of storage and transport capacity, and loss of efficiency.

Wax is a complicated blend of n-paraffin, i-paraffin and c-paraffin with carbon numbers from 18 to 65 (Lake et al. 2006). Fadairo et al. (2010) and Kasumu et al. (2013) showed that waxes are precipitated as solids with the changing thermodynamic equilibrium when the oil temperature cools down lower than the wax appearance temperature (WAT). In other words, the temperature at which the first organic wax crystalizes in oil as a deposit is referred to as the WAT. Berne-Allen et al. (1938) and Paso et al. (2009) suggested that the WAT is one of the main factors, which needs to be taken into account when developing preventative strategies for handling wax deposition in oil wells.

For a scientifically-based method to the prevention and removal of wax, it is important to take into account the conditions that cause a phase transition of paraffin to a solid-state. This process is influenced concurrently by several factors (Glushchenko et al. 2009, Ibragimov et al. 2010, Rogachev et al. 2006):

- geological, physical and technological conditions of field production;

- physicochemical properties and component composition of reservoir oil; 
- changes in thermobaric conditions along the wellbore;

- violation of hydrodynamic equilibrium;

- changes in the structure and flow rate;

- the intensity of oil degassing;

- the amount of solid contained in oil;

- water-cut;

- condition of the internal surface of the equipment (roughness).

The intensity of the wax formation depends on the predominance of one or more factors, which might vary in time and depth, hence, the amount and nature of organic deposits are not constant (Struchkov et al. 2018).

Regarding the analysis of the prevailing situation on the dewaxing of a well of the studied production object, it was found that the measures taken to remove wax deposits, for one reason or another, have low efficiency. Solving the problem of preventing the formation and removing wax deposits will reduce current and capital costs in the exploitation of high-wax oil.

One of the acknowledged methods to reduce the intensity of the formation of organic deposits in the well is to choose the optimal technological regime of its operation. During the production of the high-wax oil well using ESP, the most important operating parameters affecting the conditions for the formation of wax deposits are the changes in the ESP rotation frequency and the number of stages, as well as the buffer pressure.

Despite the fact that wax formation simulation is one of the more challenging questions facing engineers, owing to the extremely complicated and limited data, there are a number of wax simulation programs developed to predict and control wax formation, the amount of precipitated wax, and wax deposition rates.

Detailed design of production systems is required to improve the efficiency of oil production and exploitation. There are a tremendous number of software packages used to predict the crystallization process of high-molecular components of oil such us the PVTsim software package (developed by the Calsep company), the PVTP software package (developed by the Petroleum Experts company), and the OLGA and PIPESIM software packages (developed by the Schlumberger company).

One of the leading software systems in the field of analysis and optimization of oil production systems is the product of the Schlumberger Company - PIPESIM. For the most part, this software package is a wax simulation used for building and calculation of a static model of steadystate multiphase flow moving from the reservoir to the objects of the collection and preparation system. PIPESIM allows for the solution of many complicated problems with the help of numerous modules included in this package (Schlumberger PIPESIM [Electronic resource]).

The novelty of this paper is to provide a detailed study of the effect of parameters of the electric submersible pump on wax formation. In addition, this work also proposes practical recommendation for given conditions, which play a pivotal role in predicting and measuring wax formation.

\section{MATERIALS AND METHODS}

In this work, we used the results of laboratory studies of the physicochemical properties of the high-wax oil in the Kirtaelskoe field, as well as the results from modeling the movement of the specified high-wax oil along the wellbore of a well using electric submersible pump through the Schlumberger PIPESIM software package.

\section{RESULTS AND DISCUSSION}

\subsection{Initial data}

The object of the study is a hypothetical well, simulating the conditions of the Timan-Pechora oil and gas province with geometric, geological and physical parameters characterized for the 
Table 1. Well parameters.

\begin{tabular}{|c|c|}
\hline Parameter & Value \\
\hline Flow rate of the fluid at standard conditions, $\mathrm{m}^{3} / \mathrm{d}$ & 85 \\
\hline Productivity Index, $\mathrm{m}^{3} / \mathrm{d}^{*} \mathrm{MPa}$ & 15 \\
\hline Gas/oil ratio, $\mathrm{m}^{3} / \mathrm{m}^{3}$ & 72 \\
\hline Surface pressure, $\mathrm{MPa}$ & 1.8 \\
\hline Oil bubble point pressure, $\mathrm{MPa}$ & 8.8 \\
\hline Well depth, m & 3000 \\
\hline Perforation depth, m & 2925 \\
\hline Tubing depth, m & 2400 \\
\hline Average angle of inclination of the well, ${ }^{\circ}$ & 2 \\
\hline Internal diameter of the production string, $\mathrm{m}$ & 0.144 \\
\hline Internal diameter of tubing, $\mathrm{m}$ & 0.062 \\
\hline Temperature of the neutral layer, ${ }^{\circ} \mathrm{C}$ & 4 \\
\hline Depth of the neutral layer, $\mathrm{m}$ & 30 \\
\hline
\end{tabular}

Table 2. Physical and chemical properties of degassed oil from the $\mathrm{D}_{2 \mathrm{ef}}$ pool.

\begin{tabular}{lc}
\hline Main properties & Value \\
\hline Density at $20{ }^{\circ} \mathrm{C}, \mathrm{kg} / \mathrm{m}^{3}$ & 802 \\
The pour point, ${ }^{\circ} \mathrm{C}$ & 39 \\
WAT, ${ }^{\circ} \mathrm{C}$ & 43.5 \\
Hydrocarbon group composition, \% by mass: \\
Wax content $(\mathrm{wt} \%)$ & 32.3 \\
Asphaltene content $(\mathrm{wt} \%)$ & 0.7 \\
Resin content $(\mathrm{wt} \%)$ & 4.7 \\
Reservoir temperature, ${ }^{\circ} \mathrm{C}$ & 62 \\
Reservoir pressure, $\mathrm{MPa}$ & 29.1 \\
\hline
\end{tabular}

conditions of the developed oil reservoir $\mathrm{D}_{2 \mathrm{ef}}$ (given in Table 1). The temperature for the specified reservoir is $62{ }^{\circ} \mathrm{C}$, and the current reservoir pressure is $19.6 \mathrm{MPa}$.

The results of laboratory studies of the physical-chemical properties of the wellhead nonwater oil sample are shown in Table 2. Degassed oil is extremely light (density $802 \mathrm{~kg} / \mathrm{m}^{3}$ ). The pour point is $39^{\circ} \mathrm{C}$.

In terms of group analysis, the oil has a high wax content ( $32.3 \%$ by mass), and is resinous (resin content is $4.7 \%$ and asphaltene content is $0.7 \%$ by mass). Physical and chemical properties of degassed oil from the $\mathrm{D}_{2 \text { ef }}$ pool are given in Table 2.

\subsection{Pump selection}

At the first stage, a method of well productivity evaluation was applied in the form of nodal analysis. It allows us to divide the system "reservoir-well-pump" into components connected by nodal points (Guo et al. 2009), to visually evaluate the influence of various parameters on the formation productivity and the performance of the lift and submersible pump. The behavior of the well is determined by the energy of the reservoir ensuring the flow of fluid to the well and the ability of the fluid to rise to the surface. The intersection point of the inflow curve (indicator curve) and the outflow curve is called the working point of the system. Modeling of fluid flow at the bottom of the well, which determines the flow rate of the reservoir at the depression established on it was carried out by setting the well productivity index, taking into account the Vogel correction. In the developed model, the nodal point is located opposite the perforated interval. 


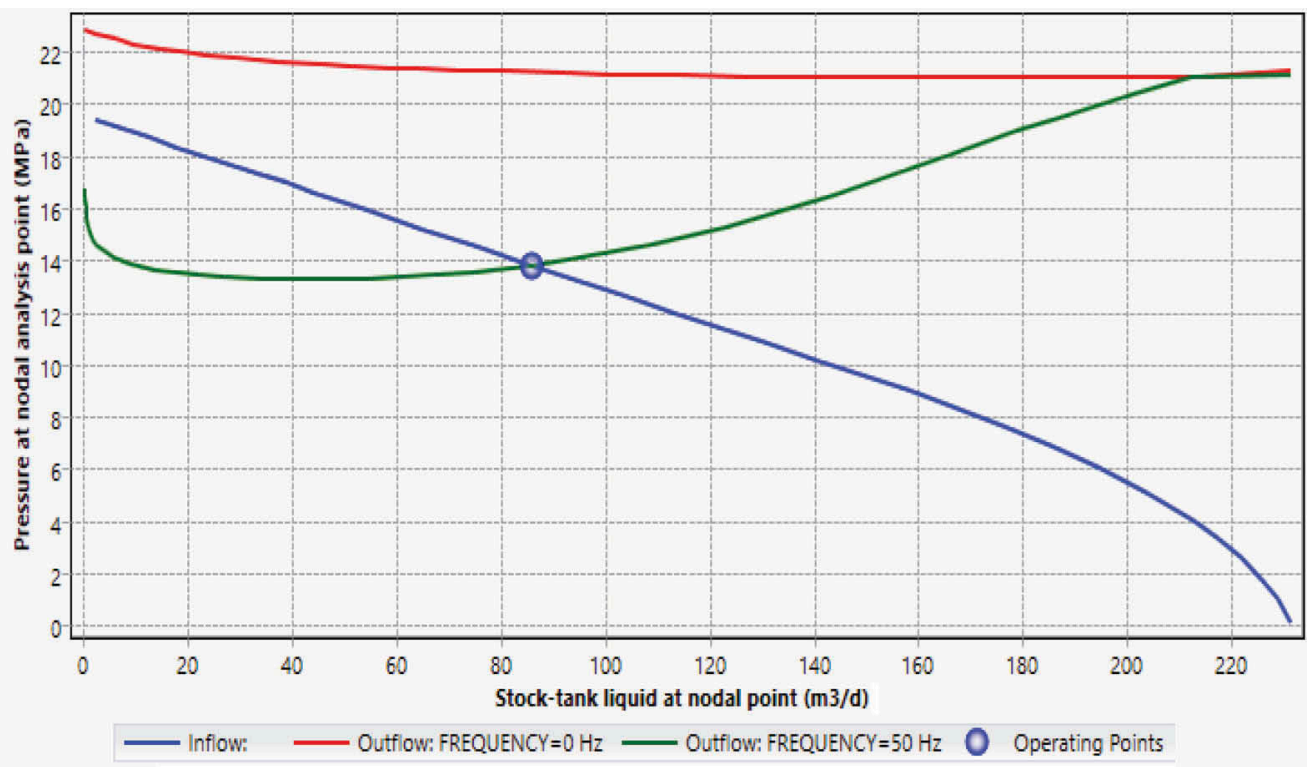

Figure 1. Combined characteristic of the reservoir-well system without a pump and with its use.

During production, the initial reservoir pressure dropped to $19.6 \mathrm{MPa}$. The use of nodal analysis makes it possible to establish that the energy for lifting the well is not enough to move the fluid from the downhole to the wellhead - well blowout is impossible (red line, Figure 1).

In order to provide the well with sufficient energy to lift fluid to the surface and achieve the planned flow rate $\left(85 \mathrm{~m}^{3} / \mathrm{day}\right)$, an ESP TD600 was chosen. The green line in Figure 1 represents the characteristic of the well with a working pump. The most suitable pump is selected from the vast database with the highest efficiency, which is made for the selected pump model $65 \%$. When choosing a pump, losses between steps, viscosity correction, and downhole separation effects were taken into account.

\subsection{Phase equilibrium diagram}

With regard to the known physical-chemical characteristics and component composition, a model of high-wax oil was developed, which allows us to determine the conditions for the wax formation in a gas-liquid mixture. The wax formation line shown on the phase diagram corresponds to the temperature of the studied wax appearance temperature $-44{ }^{\circ} \mathrm{C}$. According to the graph, at the temperature of $20^{\circ} \mathrm{C}$, the wax content is $32.3 \%$ by mass. The values of the WAT and wax mass content in the presented model are quite close to the experimentally obtained data at $20^{\circ} \mathrm{C}$ and the atmospheric pressure, given in Table 2 .

Under normal conditions, different hydrocarbon components contained in the oil form a three-phase system. At reservoir conditions (high temperature and pressure), all the components form one phase which is a liquid mixture. Oil is a multicomponent system, so the phase equilibrium diagram in the "temperature-pressure" coordinates, unlike in individual substances, is not a single curve, but an area limited by condensation line and evaporation line.

The first stage of the simulation is to plot a phase diagram of the hydrocarbon system for the $\mathrm{D}_{2 \mathrm{ef}}$ pool (Figure 2). To the left of the critical point $(\mathrm{C})$ and above the evaporation line (area 1) hydrocarbons are in a liquid state; to the right and below the condensation line (area 2) hydrocarbons are in a gaseous state. Inside the two-phase boundary between the 


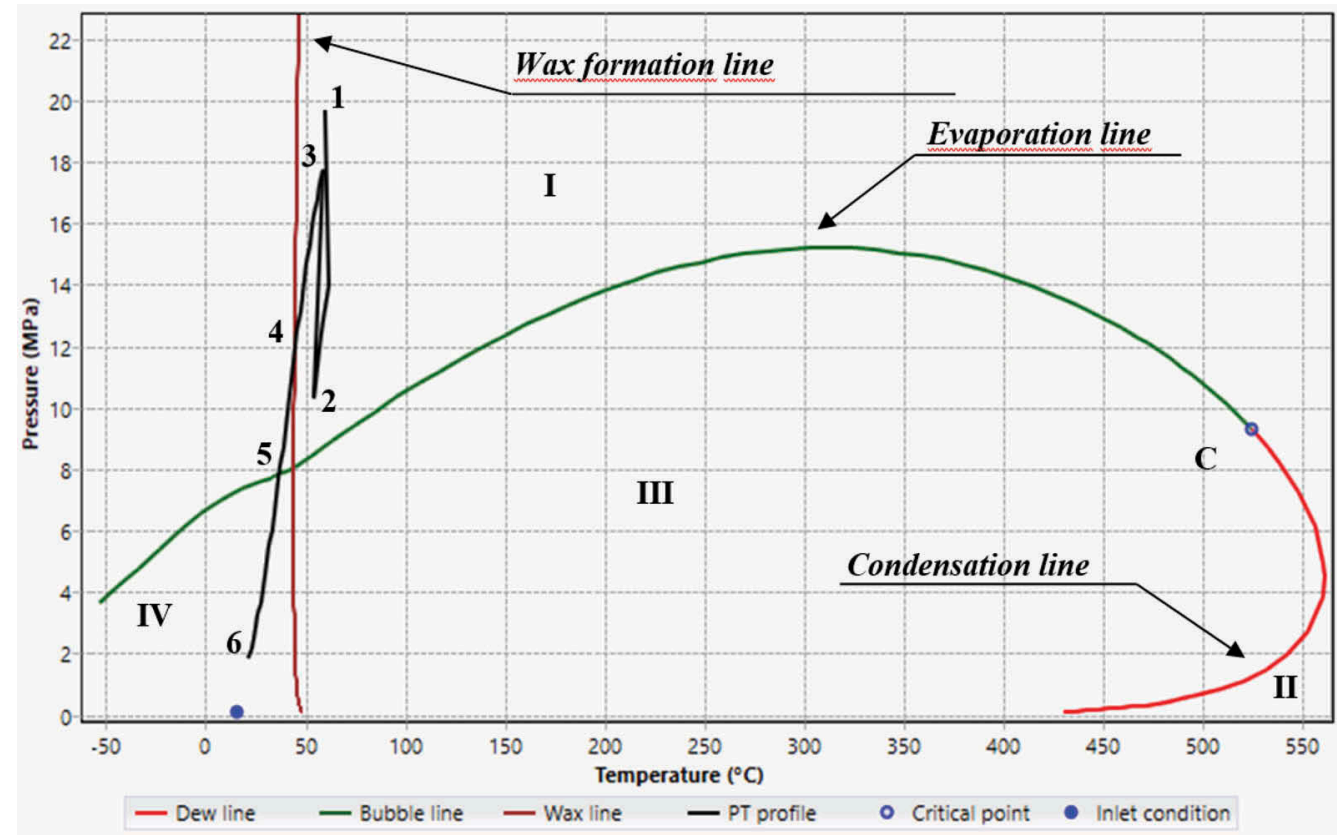

Figure 2. Phase equilibrium diagram for the $\mathrm{D}_{2 \mathrm{ef}}$ pool hydrocarbon system.

evaporation and condensation line (area 3 ) gas and liquid can coexist. When the temperature drops below the wax formation line, the system turns into a three-phase state (area 4) with an additional solid phase - wax.

Additionally, the phase diagram is a simulated PT (pressure and temperature) - profile during fluid movement from the reservoir to the wellhead. The beginning of the calculation of the model occurs at point 1 , which illustrates the reservoir conditions. Points 2 and 3 correspond to the thermobaric conditions at the intake, discharge of the ESP, and illustrate the pressure and temperature rise occurring in the pump. When moving along the tubing string, the flow temperature decreases to the WAT (point 4), which contributes to the beginning of wax formation. Then the pressure decreases to the point of oil saturation with gas (bubble point, point 5), which initiates the loss of light hydrocarbon fractions and contributes to the extensive formation of wax deposits. In the area between points 5 and 6 (wellhead), there is a movement of a 3-phase system (liquid, gas and solid particles).

\subsection{Determination of the depth of wax formation}

Figure 3 shows a comparison of the real (actual) temperature log with temperature distribution profiles along the wellbore, which is calculated by using formulas 1,2, 3 and through complex mechanical model of the vertical multiphase flow OLGAS. In this model, two types of correlations are observed: the two-phase model considering the gas-liquid flow and the three-phase model additionally counting solid particles.

The complex mechanical flow model OLGAS is applied for all tilt angles, pipe diameters, and fluid properties. In this model, we used independent continuity equations for gas and liquid droplets, which are related to interfacial mass transfer.

The wax appearance temperature curve obtained using the Coutinho model in the Multiflash module was shown in Figure 3, which allows us, when crossing with temperature profiles, to determine the depth of the formation of wax deposits in the well (Table 3).

The model Coutinho is a thermodynamic model based on the concept of predicting the formation of a solid phase. The use of this model in combination with the state equation 


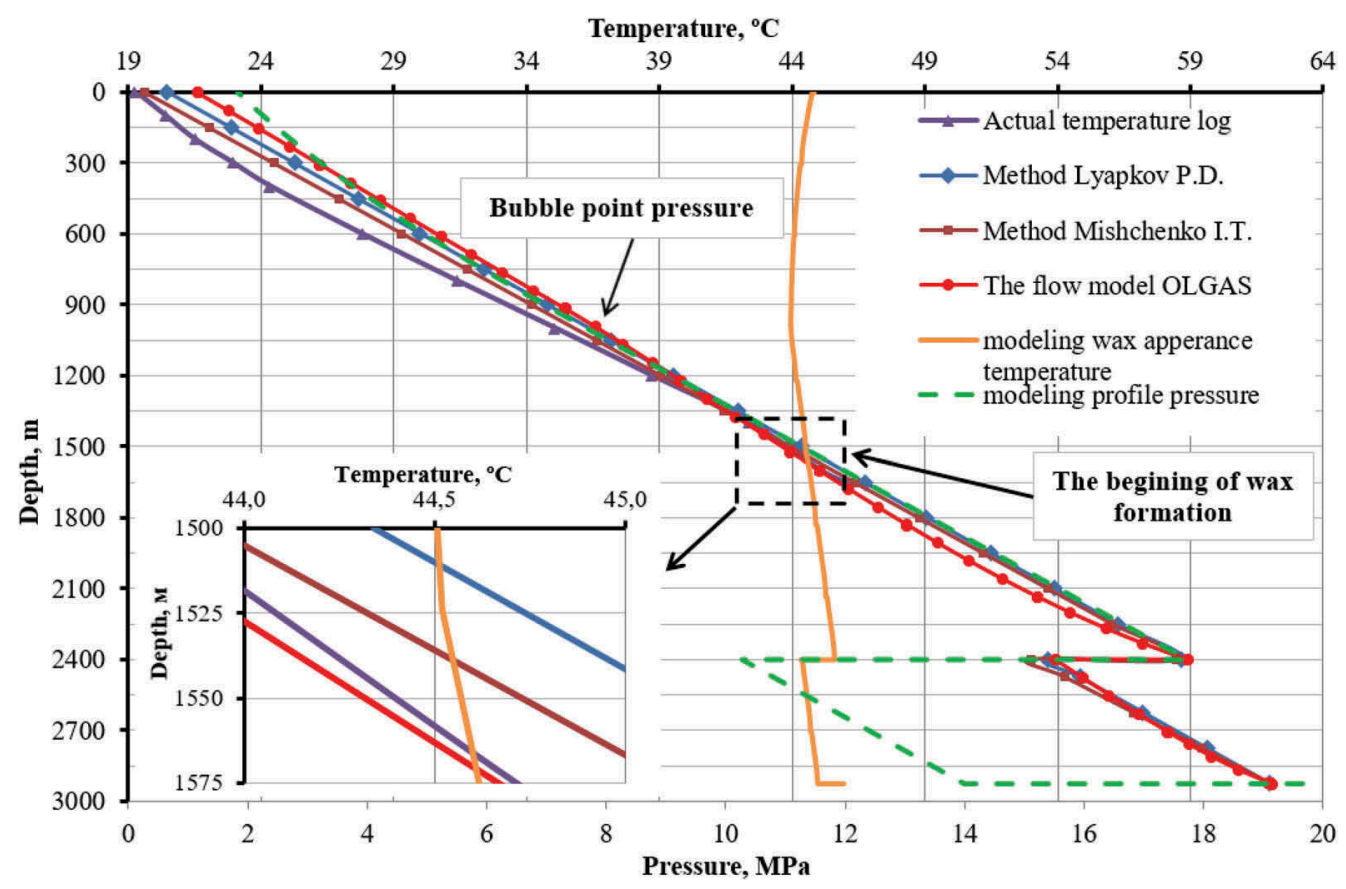

Figure 3. Determination of the depth of the formation of wax deposits.

Table 3. Determination of the depth of wax formation.

\begin{tabular}{lll}
\hline Method & WAT, ${ }^{\circ} \mathrm{C}$ & $\mathrm{H}_{\text {wax formation, }} \mathrm{m}$ \\
\hline According to Lyapkov P.D. & 44,51 & 1510 \\
According to Mishchenko I.T. & 44,55 & 1540 \\
According to actual temperature log & 44,59 & 1566 \\
According to the flow model OLGAS & 44,62 & 1572 \\
\hline
\end{tabular}

(UNIQUAC model) makes it possible to predict the behavior of oil and its model solutions at low temperatures with high accuracy (Coutinho J. et al. 2001).

Temperature distribution at the wellbore using the method of Lyapkov P.D. (Lyapkov P.D. 1987):

$$
T(H)=T_{r}-\left(L_{c}-H\right) \cdot \frac{0.0034+0.79 \cdot \omega \cdot \cos \alpha}{10 \frac{q}{86400 \cdot 20 \cdot d^{2.67}}}
$$

where $T_{r}$ is the reservoir temperature, $\mathrm{K} ; L_{c}$ is the well depth, $\mathrm{m} ; H$ is the current depth, which is measured from the wellhead, $\mathrm{m} ; \omega$ is the average geothermal gradient in the well, $\mathrm{K} / \mathrm{m}$; $\alpha$ is the angle of deviation of the well from the vertical, degree; $q$ is the flow rate, $\mathrm{m}^{3} / \mathrm{s}$; $d$ is the diameter of the lift, $\mathrm{m}$.

Temperature distribution at the wellbore using the method of Mishchenko I.T. (Mishchenko I.T. 2003):

- For tubing

$$
t(h)=t_{r}\left\{1-\frac{h}{c}\left[0.544\left(623.7 \frac{d_{t}}{Q_{m}}+1\right)\right]\right\},
$$


- For the casing string

$$
t(h)=t_{r}\left\{1-\frac{h}{c}\left[0.544\left(311.85 \frac{d_{c}}{Q_{m}}+1\right)\right]\right\}
$$

where $t_{r}$ is the reservoir temperature, ${ }^{\circ} \mathrm{C} ; h$ is the depth, which is measured from the bottom hole, $\mathrm{m} ; Q_{m}$ is the mass flow rate, $\mathrm{t} / \mathrm{d} ; d_{t}$ is the internal diameter of the tubing, $\mathrm{m} ; d_{c}$ is the internal diameter of casing string, $\mathrm{m} ; c$ is the specific heat of well product, $\mathrm{J} / \mathrm{kg} \cdot{ }^{\circ} \mathrm{C}$.

Thus, the comparison of the actual temperature log with the temperature distribution profiles along the wellbore, which was calculated according to the methods of Lyapkov P.D., Mishchenko I.T. and built using the complex mechanical model of the vertical multiphase flow OLGAS, showed that the study has an excellent result. For the given conditions, the greatest convergence with field study results of the temperature distribution along the wellbore and the actual depth of the beginning of the wax formation is given by using the multiphase flow model OLGAS.

\subsection{The nature of the change in the wax appearance temperature}

As previously noted, the WAT is known as the temperature at which wax from the dissolved state transfers to the solid phase (the first wax crystal is deposited in the oil). This parameter is influenced by many factors, which are: physical-chemical properties, component composition of reservoir oil, wax content, degassing intensity, pressure gradient along the wellbore (Kamenshchikov F.A. 2005).

Figure 4 Shows the joint profile of the wax appearance temperature and pressure along the wellbore. It is important to notice that the nature of changes in these parameters corresponds to the phase equilibrium diagram of the hydrocarbon system (Figure 3).

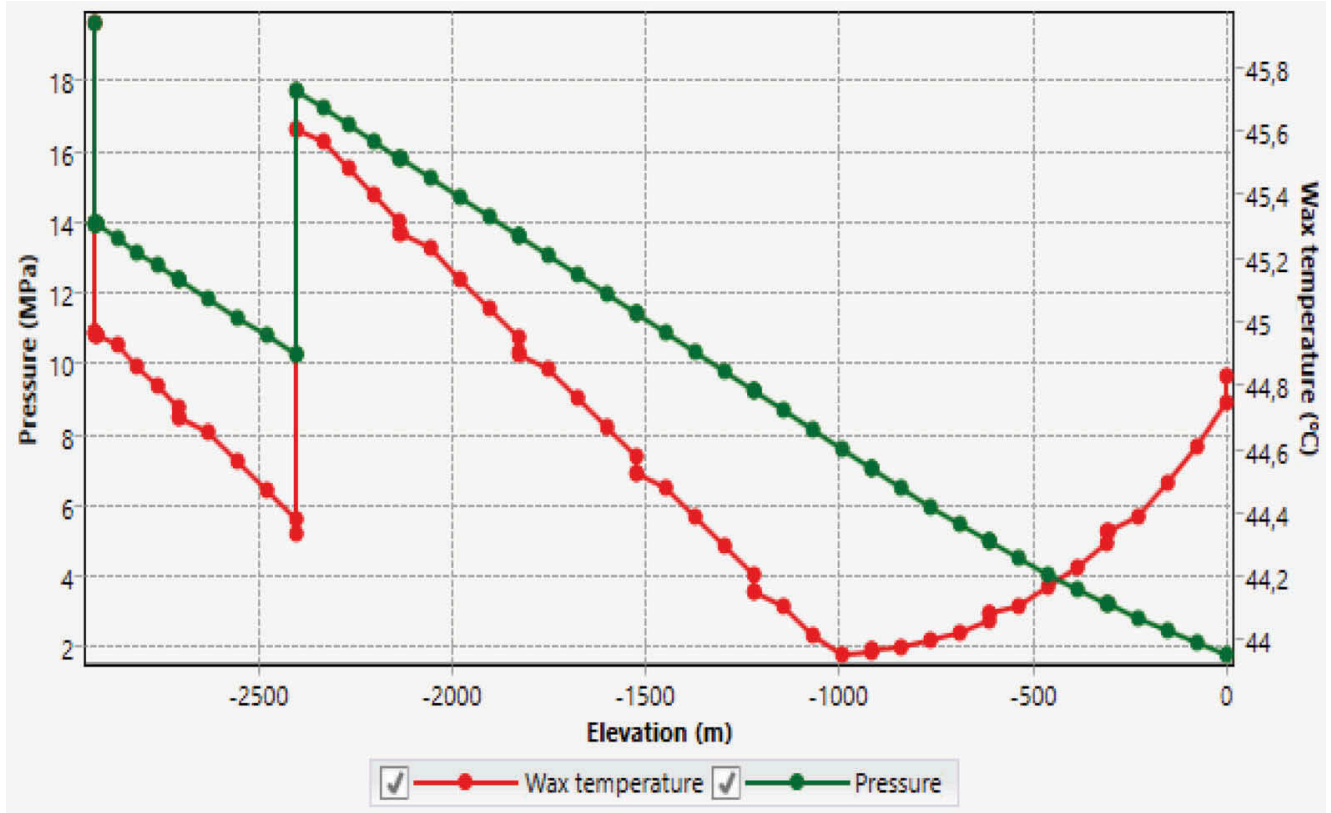

Figure 4. The pressure profile and the wax appearance temperature. 
The decrease in the WAT as it moves to the bottom of the well is due to the manifestation of the throttle effect when creating a depression on the reservoir. Moreover, a significant increase in the WAT occurs in the pump, which is caused by a sharp increase in the pressure in the system. In the sections from the perforation interval to the pump intake $(2925-2400 \mathrm{~m})$ and from the pump discharge to the "bubble point" $(2400-1000 \mathrm{~m})$, there is a linear dependence of the decline in wax appearance temperature with decreasing pressure in the system. Starting from a depth of 1000 meters, an increase in the wax appearance temperature is observed, which is due to the intensive release of light oil fractions and, consequently, a decrease in the solvent capacity of oil relative to (compared to) wax, as well as due to the cooling of the oil flow in the wellbore. It should be noted that the gas globules arising in this process are mass-exchange promoters of the growth of wax crystals (Pashali A.A. et al. 2011 \& Tronov V.P. 1970).

\subsection{The effect of the water cut of the test oil on the depth of wax formation}

The study of Glushchenko V.N. (Glushchenko V.N. et al. 2009) presents a thorough analysis of the literature and field material focused on the effect of water-cut on the formation of organic solids. In many works, a decrease in the intensity of the wax formation with an increase in water-cut of wells production was demonstrated. This owes to a decrease in adhesion to the hydrophilic steel surface, a decrease in the rate of cooling due to the greater heat capacity of water compared to oil. In Figure 5, it can be seen that with an increase in water cut, the wellhead temperature increases due to a decrease in the rate of cooling of the flow.

Additionally, in the work (Glushchenko V.N. et al. 2009), a number of researchers were highlighted, whose studies showed the negative effect of water cut. This is explained by the general decrease in the temperature of the watering fields, a significant gas absorption by water with a decrease in the wax solubility in oil, and an increase in the WAT by several degrees.

The simulation results showed that with an increase in the water cut of well production, there is a decrease in the depth of wax formation in the tubing string (Figure 6).

Thus, reducing the interval of wax formation in the well for the given conditions is caused by a decrease in the portion of high-molecular hydrocarbons in the well production during the field development, hydrophilization of the internal surface of the tubing string, as well as a decrease in the rate of flow cooling.

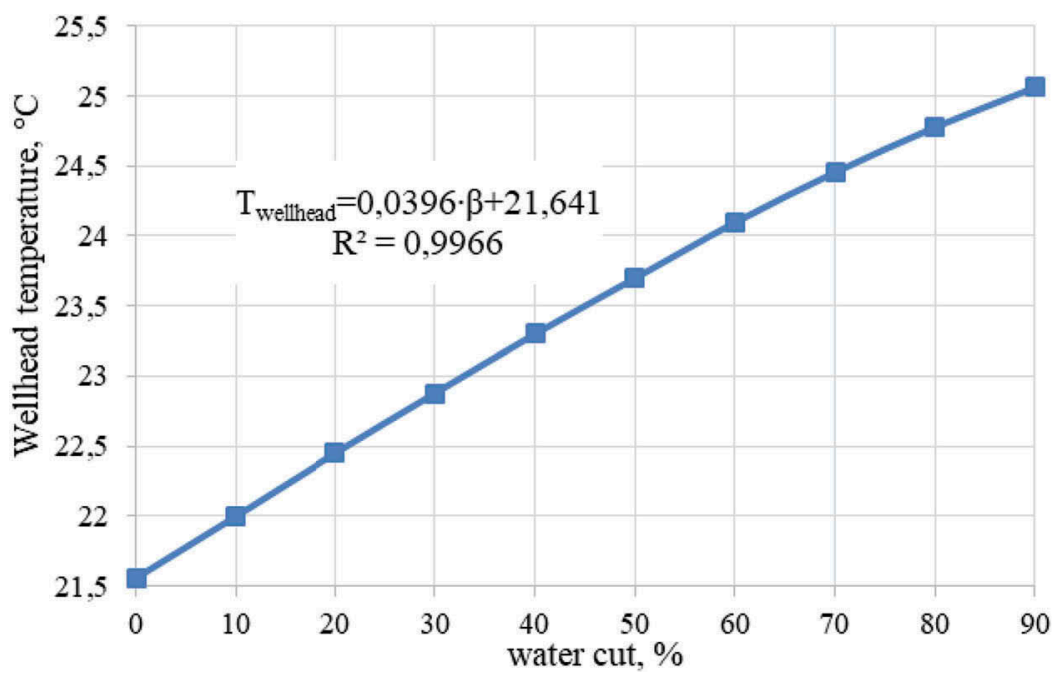

Figure 5. The dependence of wellhead temperature on water cut. 


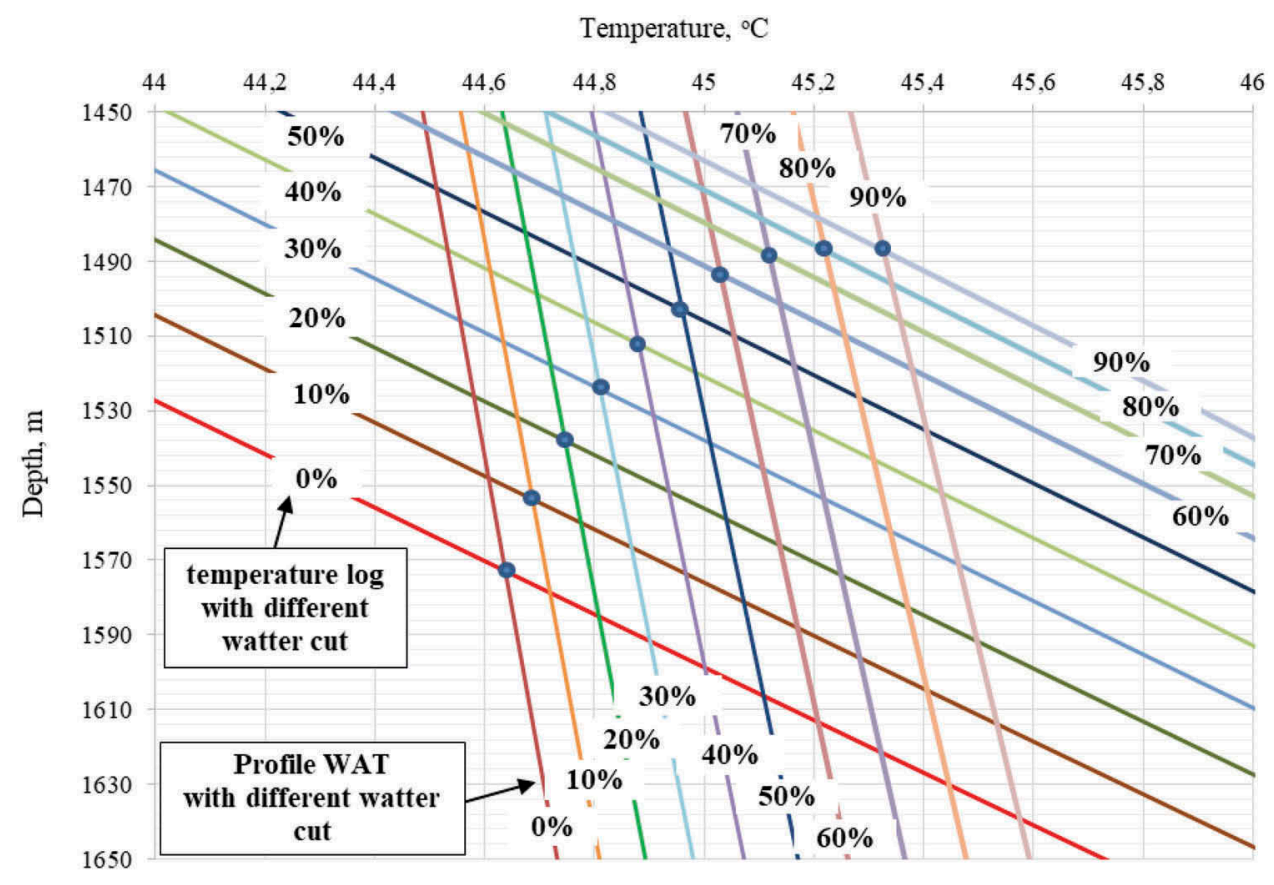

Figure 6. Dependence of the wax formation depth in the well with an increase in water cut.

\subsection{The influence of the buffer pressure on the depth of wax formation}

A considerable amount of field data demonstrates a reverse dependence of the residual gas saturation value of oil to the depth of wax formation in the wellbore (Glushchenko V.N. et al. 2009). For instance, in the Zhanazhol field, an increase in wellhead pressure prevented a sharp degassing, which led to a sharp decrease in the wax formation. Another example is the production of high-wax oil in the Tengutinskaya area in Kazakhstan. At the beginning of field operation with a high gas factor, there were no complications with the formation of wax deposits. During the development of the reservoir, the reservoir, buffer pressures, and the gas factor decrease, which led to intensive waxing of underground and surface equipment.

Hence, one of the effective methods to handle wax formation is to prevent the negative impact of the released gas by using the choke restriction method to increase the buffer pressure (Glushchenko V.N. et al. 2009). The positive effect is to reduce the time finding wells with a simultaneous increase in their flow rates.

The obtained simulation results confirmed that an increase in backpressure at the wellhead leads to a shift in the depth of the start of degassing up along the wellbore (Figure 7). From this point of view, an increase in the buffer pressure at the wellhead can serve as one of the methods for preventing wax formation in the tubing on the condition that the wax formation interval is located above the point of initial degassing.

For the given conditions, when the formation of organic deposits in the wellbore occurs before the start of oil degassing, a negative result is observed, at which point an increase in buffer pressure leads to an increase in the WAT and, therefore, an earlier onset in the formation of organic deposits in the wellbore (Figure 8). Thus, the area of effective application of the choke restriction method as a way to cope with the formation of ARPD has been identified.

In the above example, a sensitivity assessment tool was used for the boundary conditions of the model. It is necessary to consider that when changing one parameter in the model, all the others remain unchanged. 


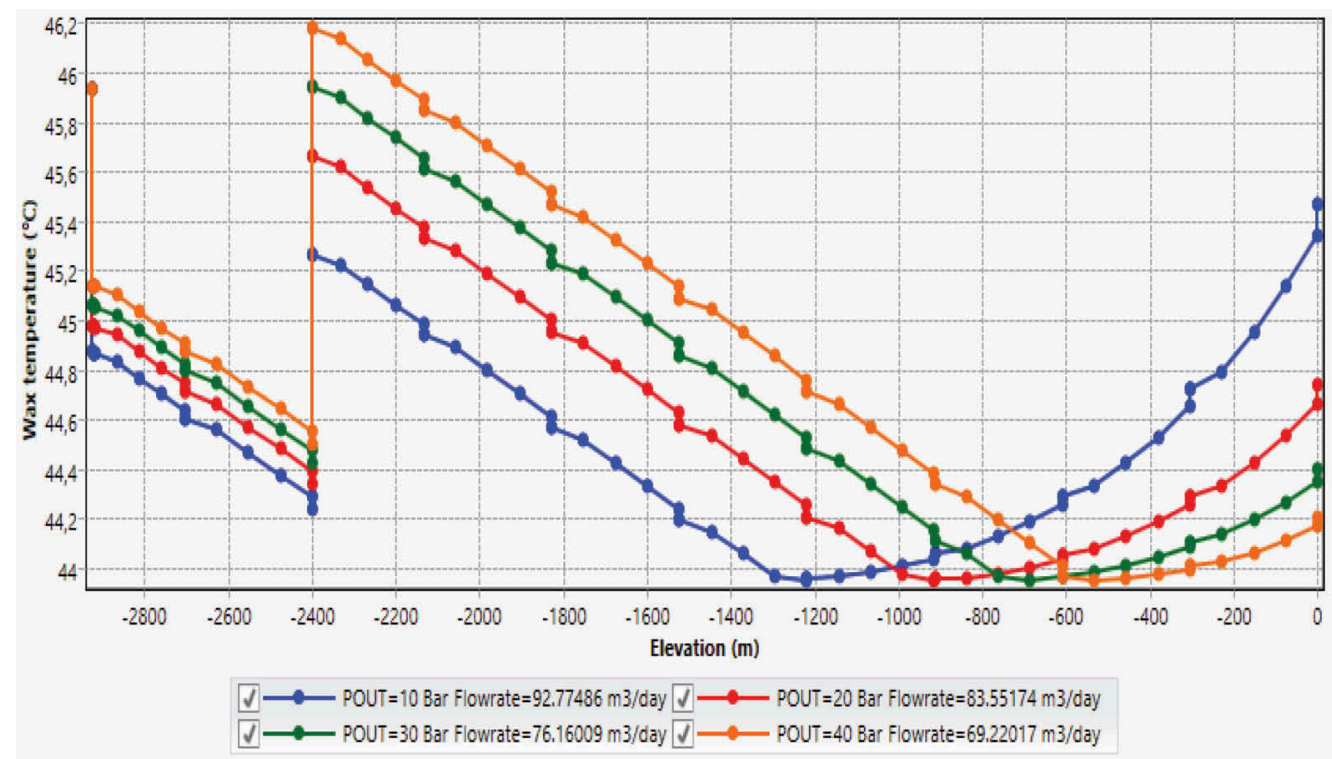

Figure 7. Change in the WAT when creating different buffer pressure.

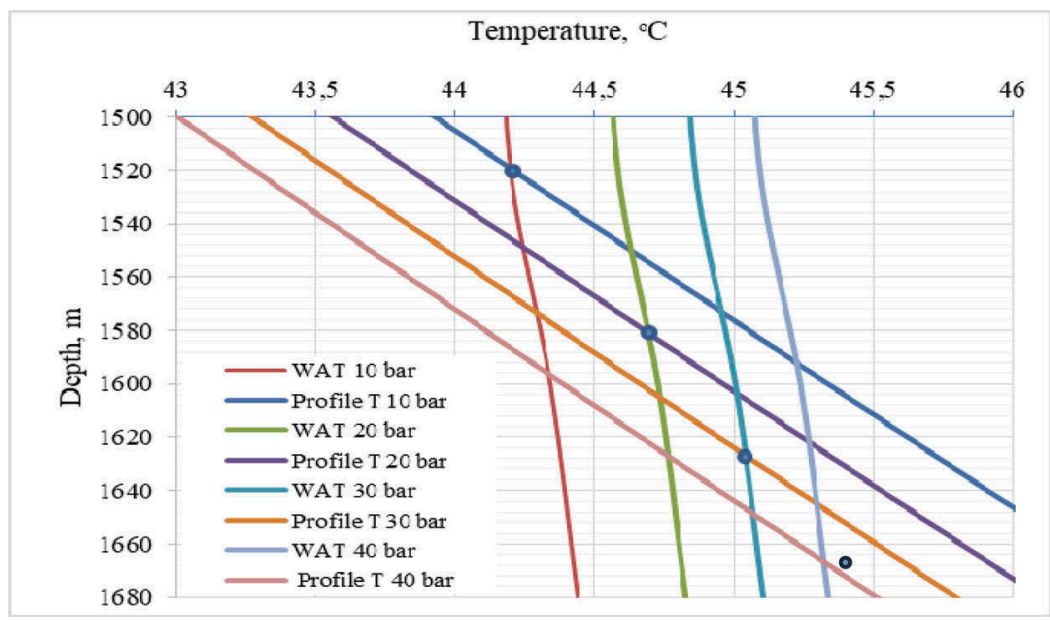

Figure 8. The influence of buffer pressure on the depth of wax formation.

\subsection{The effect of the rotational frequency of the ESP on the depth of wax formation}

One of the most important parameters that affect the intensity of the wax formation of the downhole equipment is the flow rate. Acceleration of the oil flow leads to a decrease in fluctuation of temperature along the wellbore, a change in the structure and dispersion of the gasliquid flow as well as a decrease in the rate of solid deposits accumulation. In general, a positive effect of the parameter under consideration is perceived when it changes to a certain critical value, corresponding the transition from a laminar to a turbulent flow regime (Glushchenko V.N. et al. 2009, Ibragimov N.G. et al. 2010 \& Coutinho J. et al. 2001).

Figure 9 Shows the change in the depth of wax formation in the well depending on the rotation frequency of the ESP. Furthermore, the flow rate can be influenced by change in the 


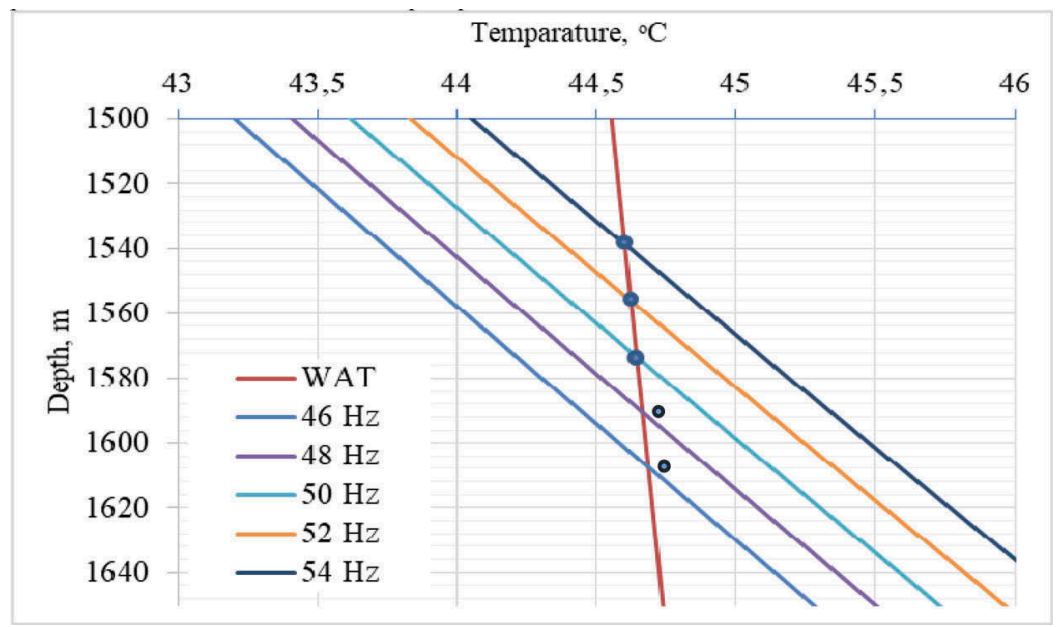

Figure 9. Effect of ESP rotation frequency on the depth of wax formation in the well.

number of stages in the pump and the diameter of the tubing, which also leads to change in the pressure-flow characteristics of the pump.

\section{CONCLUSIONS}

1. By modeling the movement of high-wax oil in wellbores, we are be able to study the influence of various factors affecting the depth of the formation of organic deposits.

2. High convergence of the actual temperature log with the calculated temperature profiles with regard to the methods of Lyapkov P.D. and Mishchenko I.T. was obtained. This allows us to rely on the accuracy of these methods on the condition that the results of field studies of the temperature distribution in the wellbore are not available. Nevertheless, for the given conditions, the closest to actual value of the depth of organic deposit formation was obtained through the complex mechanistic model of the vertical multiphase flow OLGAS.

3. The nature of the change in WAT along the wellbore was determined. It is important to note that those changes were highly noticeable when creating a depression on the reservoir and increasing the pressure in the ESP. During degassing, the WAT increases due to a decrease in the content of light fractions.

4. Temperature is considered as one of the key factors affecting wax formation in wells. It is recommended to use a nominal size ESP with higher productivity than that, which is required to achieve the planned flow rate, which will provide additional heating to the production of the well.

5. The influence of ESP rotation frequency on the depth of wax formation was established. On top of the increase in frequency, it is possible to influence the growth of the flow rate by reducing the internal diameter of the tubing and adding the number of stages, which also leads to a change in the pressure-flow characteristics of the pump.

6. The dependence of the depth of wax formation along the wellbore on the water content of the high-wax oil was established. The decrease in the interval of wax formation in the well is the result of the reduction in the proportion of high-molecular hydrocarbons in the well production during the development of the field, the hydrophilization of the internal surface of the tubing string, and the decrease in the rate of flow cooling.

7. Identified the area of effective application of the choke restriction method (an increase in buffer pressure) as a way to handle wax formation. A positive effect is observed when the formation of deposits in the well occurs after the start of degassing. Contrarily, a negative 
result is observed, when an increase in the buffer pressure leads to an increase in the WAT and consequently, an earlier onset in the formation of organic deposits in the wellbore.

\section{ACKNOWLEDGMENTS}

We acknowledge Evgeny A. Kibirev, head of oil production technology, technology and methods of the oil production department (Gazpromneft-NTC LLC, Saint Petersburg, Russian Federation), for his assistance during the experiments. We acknowledge Dr. M.K. Rogachev for his assistance during the experiments. Finally, we would like to thank Saint-Petersburg mining university (Saint-Petersburg, Russian Federation) for providing laboratory equipment, support and samples for this research.

\section{REFERENCES}

Bern, P.A., Withers, V.R., \& Cairns, R.J. 1980. Wax deposition in crude oil pipelines. In European offshore technology conference and exhibition. Society of Petroleum Engineers.

Berne-Allen, Jr.A., \& Work, L.T. 1938. Solubility of refined paraffin waxes in petroleum fractions. Industrial \& Engineering Chemistry, 30(7): 806-812.

Brown, T.S., Niesen, V.G., and Erickson, D.D., 1993, "Measurement and Prediction of the Kinetics of Paraffin Deposition", $68^{\text {th }}$ Annual Conference of the Society of Petroleum Engineers, paper no. SPE 26548.

Creek, J.L., Lund, H.J., Brill, J.P., \& Volk, M. 1999. Wax deposition in single phase flow. Fluid Phase Equilibria, 158, 801-811.

Fadairo, A.S. A., Ameloko, A., Ako, C.T., \& Duyilemi, O. 2010. Modeling of wax deposition during oil production using a two-phase flash calculation. Petroleum \& Coal, 52(3): 193-202.

Glushchenko, V.N., Silin, V.N., \&\#x0026; Gerin, Yu.G. 2009. Prevention and elimination of asphaltene-resin-paraffin deposits. Oilfield chemistry: $480 \mathrm{p}$.

Guo, B., Song, S., Chacko, J. and Ghalambor, A. "Offshore Pipelines”, Elesvier Inc., Oxford, UK, 2005.

Guozhong, Z., \& Gang, L. 2010. Study on the wax deposition of waxy crude in pipelines and its application. Journal of Petroleum Science and Engineering, 70(1-2), 1-9.

Huang, Z, Zheng, S., \& Fogler, H.S. 2016. Wax Deposition: Experimental Characterizations, Theoretical Modeling, and Field Practices. CRC Press, Boca Raton.

Ibragimov, N.G., Tronov, V.P., \& Guskova, I.A. 2010. Theory and practice of methods for controlling organic deposits in the late stages of oil field development. - $240 \mathrm{p}$.

Jennings, D.W., \& Weispfennig, K. 2005. Experimental solubility data of various n-alkane waxes: effects of alkane chain length, alkane odd versus even carbon number structures, and solvent chemistry on solubility. Fluid phase equilibria, 227(1), 27-35.

Jung, S.Y., Lee, D.G., \& Lim, J.S. 2014. A simulation study of wax deposition in subsea oil production system. In The Twenty-fourth International Ocean and Polar Engineering Conference. International Society of Offshore and Polar Engineers.

Kamenshchikov, F.A. 2005. Thermal dewaxing wells. Izhevsk: 254 p.

Kasumu, A.S., Arumugam, S., \& Mehrotra, A. K. 2013. Effect of cooling rate on the wax precipitation temperature of "waxy" mixtures. Fuel, 103, 1144-1147.

Kohse, B.F., \& Nghiem, L.X. 2006. Asphaltene and waxes. Petroleum. Engineering Handbook. Society of Petroleum Engineering, Richardson Texas, USA.

Lake, L.W., Kohse, B.F., Fanchi, J.R., \& Nghiem, L.X. 2006. Petroleum Engineering Handbook: Volume I General Engineering. SPE, Texas, USA: 397-453.

Leontaritis, K.J., \& Geroulis, E. 2011. Wax Deposition Correlation-Application in Multiphase Wax Deposition Models. In Offshore Technology Conference. Offshore Technology Conference.

Lyapkov, P.D.1987. Selection of the installation of a submersible centrifugal pump to the well. M.: MING.

Mishchenko, I.T. 2003. Oil Well Production: A Textbook for High Schools. M.: FSUE Publishing House "Oil and Gas" Russian State University of Oil and Gas named after IM Gubkin. - 816 p.

Pan, H., Firoozabadi, A., \& Fotland, P. 1997. Pressure and composition effect on wax precipitation: experimental data and model results. SPE Production \& Facilities, 12(04), 250-258.

Pashali, A.A., Mikhailov, V.G., \& Petrov, P.V. 2011. Investigation of the effect of the concentration of gas bubbles on the value of the coefficient of natural separation//Bulletin of the Ufa State Aviation Technical University, T. 15. - No. 1 (41). 
Paso, K., Kallevik, H., \& Sjoblom, J. 2009. Measurement of wax appearance temperature using near-infrared (NIR) scattering. Energy \& Fuels, 23(10), 4988-4994.

Rogachev M.K., Strizhnev K.V. Fighting complications in oil production. Nedra, 2006, 296 p.

Schlumberger PIPESIM [Electronic resource]. - Access mode: http://www.sis.slb.ru/pipesim/(accessed date $04 / 15 / 18$ ).

Struchkov, I.A., \& Rogachev, M.K. 2018. The challenges of waxy oil production in a Russian oil field and laboratory investigations. Journal of Petroleum science and Engineering, 163, 91-99.

Tronov, V.P. 1970. Mechanism of the formation of resin-paraffin deposits and the fight against them/I M.: Nedra, T. 192. - p. 5. 